\section{Creative thinking}

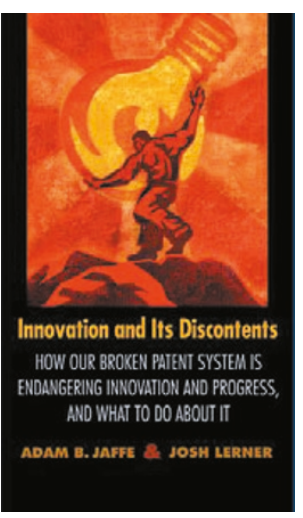

Innovation and Its Discontents: How Our Broken Patent System is Endangering Innovation and Progress, and What to Do About It

\section{by Adam B. Jaffe and Josh Lerner}

Princeton University Press, 2004

207 pp. cloth, $\$ 29.95$

ISBN 0-691-11725-X

\section{Reviewed by Bruce Berman}

Engineering ideas to provide solutions and create value is as much the province of informed researchers as it is of lawyers and bankers. Innovation and Its Discontents, a slim, engaging book by two Massachusetts economists, has stirred up its fair share of controversy. It provides a timely perspective about the inner workings of the United States patent system and how the US Patent and Trademark Office (USPTO) has fallen into disrepair. Researchers, investors and attorneys alike will benefit from the authors' rich historical insights, as well as from listening to their recommendations for improving the system, which they believe impedes prosperity.

Jaffe and Lerner argue that by allowing overly broad and "obvious" patents, the USPTO and the courts are a veritable monkey wrench in the machinery of American progress-especially in new areas particularly susceptible to poor patent quality, including business methods, software and biotechnology. However, despite these beliefs and their academic standing (Brandeis University and Harvard Business School, respectively) they claim to be not "anti-patent" but "anti-bad patent."

Hastily issued patents are a problem when disputes arise. Proving an asserter's patent invalid may be costly and time consuming, but subsequent enforcement of a patent found to be valid is a legitimate and healthy exercise of rights that helps to confer value and keep companies on the straight and narrow. Without enforcement, patent value, shareholder value and innovation would suffer, and if there were no challenges, useful patents would be even scarcer.

At the root of the problem, say Jaffe and Lerner, is the Court of Appeals for the Federal Circuit (CAFC). The CAFC was established in 1982 to hear patent appeals and provide more consistent verdicts. How the court has interpreted patent law, argue the authors,

Bruce Berman is the editor of From Ideas to Assets: Investing Wisely in Intellectual Property (John Wiley \& Sons) and Hidden Value: Profiting from the Intellectual Property Economy (Euromoney Institutional Investor). He is at work on a new book about the business of innovation. e-mail:bberman@brodyberman.com has not only made patents easier to obtain, but "easier to enforce against others, easier to get large financial awards, and...harder for those accused of infringing patents to challenge the patents' validity." In the years preceding the CAFC, compulsory patent licensing made it undesirable for many companies to file them to avoid antitrust sanctions. The authors believe that a perfect storm-buffeted by strong patent holders' rights, USPTO under-staffing, explosive technology growth and robust capital markets-has triggered an "overcorrection."

'Patent troll' is the term sometimes used for a plaintiff who is looking for a quick settlement, and who knows full well that its patents are unlikely to be upheld. Trolls hope to obtain settlements below the cost of the necessary legal action to expose them-usually \$1 million or more. However, Jaffe and Lerner fail to distinguish between these dubious owners who coerce companies with deep pockets into throwing in the towel, and the majority of legitimate asserters, large and small, who have a duty to their shareholders to generate intellectual property value.

Innovation and Its Discontents is recommended for its take on patent history, as well as for opening the lid on legal strategies, such as infringement assertions, that position patents for maximum value. The authors' suggestions for improving quality are generally sound. They include the introduction of a more effective reexamination or post grant "opposition" procedure to knock out patents that should have never been issued, diverting fewer USPTO fees, and hiring and retaining more examiners.

Where Jaffe and Lerner miss the mark is in hoisting a distress signal that the broken US patent system, tipped in favor of patent holders' rights, is stifling innovation. In fact, the US maintains the strongest patent protection for software. Surely, many patents issued to wellknown companies would, under scrutiny, be found invalid. Still, the US software industry is by all standards the most robust in the world. Businesses of all sizes, as well as independent inventors, have not been deterred from filing software patents, despite the almost four-year period it takes to issue them. Erring on the side of the inventor, it would seem, facilitates more innovation than it might quell.

The authors believe that expanded patentability in biotechnology is of serious concern. "The granting of overly broad patents [such as on the human genome] that appear obvious in light of previous developments, and which grant broad rights that seem to cover with one patent many diverse possible uses," creates significant problems, they write. Jaffe and Lerner are not wrong, but they have no confidence in the ability of the legal system and markets to self-correct and resolve most disputes equitably.

Poor patents are a serious problem. But narrowing their scope can only provide so much relief. Even with the proper resources, it is difficult for examiners to anticipate potential disputes, or how new technologies will evolve. Software and biotechnology inventions, in particular, have an ambiguous relationship to the products that they may one day protect. Innovation and Its Discontents is a more substantial primer than it is a polemic. It provides a thoughtful context for people affected by intellectual property rights or engaged in creating them, recommendations for saving innovation aside. 